\title{
Suicide prevention: a study of patients' views
}

\author{
JOHN M. EAGLES, DAWN P. CARSON, ANNABEL BEGG and SIMON A. NAJI
}

\author{
Background Suicide prevention \\ strategies are usually formulated without \\ seeking the views of people with \\ psychiatric illnesses.
}

Aims To establish what helped patients with severe psychiatric illness when they felt suicidal.

\begin{abstract}
Method A semi-structured interview was constructed following transcribed interviews with 12 patients. This was administered to 59 out-patients with serious and enduring mental illness, focusing on factors they found helpful or unhelpful when at their most despairing.
\end{abstract}

Results Three-quarters of patients were in contact with psychiatric services when feeling at their lowest, and this contact was generally deemed to be helpful. Social networks were considered just as helpful as psychiatric services by the half of patients who discussed their feelings with friends or relatives. Religious beliefs and affiliations were helpful. Negative influences included the media and the stigma of psychiatric illness.

\section{Conclusions Efforts at suicide} prevention might usefully focus on enhancing patients' social networks, increasing the likelihood of early contact with psychiatric services and decreasing the stigma attached to psychiatric illness. Larger studies of patients exposed to different service models would be informative.

Declaration of interest None.
Research into suicide is often predicated on the expectation that the findings may be helpfully applied to suicide prevention, even though this expectation can be viewed as optimistic for much research into the subject (Geddes, 1999; Mortensen, 1999; Eagles et al, 2001). In recent years the psychological autopsy method has been used increasingly, despite its methodological problems (Hawton et al, 1998). Notably, deficiencies of this method include the acquisition of a retrospective account from a third party, and the impossibility of hearing directly which factors or interventions might have averted the suicide. For psychiatric services, our main opportunity of influencing suicidality is, perhaps selfevidently, with patients with mental illness. In an era when involvement of service users in policy-making and in research is increasingly advocated (Faulkner \& Thomas, 2002), it is perhaps surprising that patients' views on suicide prevention strategies have not hitherto been sought systematically. On the basis that most people who suffer from severe and enduring mental illness will at some point have contemplated or attempted suicide, we thought that it might be instructive to ask such patients about factors which they felt might have helped prevent them from contemplating suicide.

\section{METHOD}

Three of the authors (D.P.C., J.M.E., S.A.N.) considered and discussed the many factors that might protect from, or give rise to, suicidality among patients with severe and enduring mental illness. These factors formed a loose structure for detailed, freeranging, tape-recorded interviews with 12 patients who were recruited from J.M.E.'s community mental health team case-load. These interviews were transcribed and the transcriptions were scrutinised with a view to the extraction of themes and the design of a semi-structured questionnaire. Thirteen consultant colleagues were then asked to give names of suitable patients for interview. From each team, we asked for up to ten patients with a clinical diagnosis of schizophrenia or schizoaffective disorder and for up to ten patients diagnosed with either bipolar or unipolar recurrent affective disorders. We requested that the patients selected should be as representative as possible of the consultant's overall patient population, excluding patients only if it was felt that it might be counter-therapeutic to approach them. Participants who were currently receiving out-patient treatment were requested, but partly as a criterion of severity of illness, such participants should have had at least one previous psychiatric admission. The consultants from whom patients' names were requested worked in teams based across Aberdeen and Aberdeenshire; patients were offered travel expenses to attend interviews. The researchers (D.P.C. and A.B.) contacted the patients directly, by letter and/or by telephone, explained the purpose of the interview and invited their participation. An average interview was 60-90 minutes in duration. Most interviews took place at the Royal Cornhill Hospital, Aberdeen; a few were held in general practitioners' surgeries and a few in the patients' homes. Approval to conduct the study was obtained from the Grampian Research Ethics Committee.

We anticipated that most of the patients would have at times felt very low and despairing, and that for many of them this would have given rise to suicidal feelings and/or actions. Patients were asked to identify the time during their illness when they felt at their most despairing, and most of the interview focused on this period with regard to factors that might have alleviated or precipitated suicidal feelings.

Of the 250 patients deemed potentially suitable by their consultant psychiatrists, letters inviting participation were sent to 242 . Of these patients 164 responded, of whom 86 agreed to be interviewed. Appointments were agreed with 67 patients, of whom 59 attended and their interviews gave rise to useable data. Of these 59 patients, 27 were male and 32 were female. Their mean age at the time of interview was 47.4 years (s.d.=12.7 years). The mean duration of illness (from time of first presentation to services) was 16.2 years (s.d.=12.9 years). Diagnostically, 17 participants had schizophrenia or schizoaffective disorder, 18 had bipolar affective disorder and 24 had a recurrent depressive disorder. 
Table I Frequency and helpfulness of contact when patients $(n=59)$ felt at their most despairing

\begin{tabular}{|c|c|c|c|c|c|c|}
\hline \multirow[t]{2}{*}{ Contact } & \multirow{2}{*}{$\begin{array}{l}\text { Patients having contact } \\
\qquad n(\%)\end{array}$} & \multicolumn{5}{|c|}{ If in contact, how helpful was it? } \\
\hline & & $\begin{array}{c}\text { Helped a great deal } \\
\qquad n\end{array}$ & $\begin{array}{c}\text { Helped a bit } \\
n\end{array}$ & $\begin{array}{c}\text { No better/no worse } \\
n\end{array}$ & $\begin{array}{c}\text { A bit worse } \\
n\end{array}$ & $\begin{array}{c}\text { A lot worse } \\
n\end{array}$ \\
\hline General practitioner & $37(63)$ & 13 & 10 & II & 2 & 1 \\
\hline Psychiatric services & $45(76)$ & 26 & II & 5 & 2 & 1 \\
\hline Other helping agencies & $19(32)$ & 2 & 5 & 8 & 3 & I \\
\hline Discussion within social network & $32(54)$ & 20 & 5 & 5 & I & 1 \\
\hline
\end{tabular}

In response to the question, 'Have there been times in your life when you have thought that you couldn't go on any longer?', 55 participants $(93 \%)$ answered 'yes'. Of these, 50 patients $(91 \%)$ had specifically considered suicide, and 35 (59\% of all participants) said that they had made one or more suicide attempts. For only 26 of these 35 patients was there a record of deliberate self-harm in their case records.

\section{RESULTS}

\section{People, services and strategies used}

Of the 59 patients, 23 (39\%) described feeling at their worst during their first episode of illness, before they had had contact with psychiatric services. Although contact sometimes ensued quite rapidly thereafter, 14 patients $(24 \%)$ were not in contact with psychiatric services at all during this time and $23(39 \%)$ did not see a psychiatrist. Similarly, 22 patients $(37 \%)$ reported no contact with their general practitioner while they were at their most despairing. Contact with other helping agencies was even less common. Only 7 patients $(12 \%)$ visited a drop-in centre, $5(9 \%)$ attended patient support groups, $8(14 \%)$ telephoned the Samaritans and $2(3 \%)$ contacted other telephone helplines. Patients were asked whether, when they were at their worst, they had been able to discuss their feelings and thoughts with people in their social network such as their spouses or partners, families and friends. Only 32 patients (54\%) had done so. When at their worst, 29 patients (49\%) had religious beliefs in their minds and 22 $(37 \%)$ reported praying. Forty-one patients $(69 \%)$ had deployed self-help strategies such as problem-solving or distraction.

\section{What was helpful?}

Where appropriate, patients were asked to rate the helpfulness of contacts and other factors. A comparison of the helpfulness of contacts is shown in Table 1. For statistical comparisons, these relatively small numbers were collapsed to yield categories of 'helpful' (helped a great deal or helped a bit) and 'not helpful' (no better/no worse, a bit worse, a lot worse). Statistically significant differences (all with 1 degree of freedom) were as follows: psychiatric services were deemed more helpful than general practitioners $\left(\chi^{2}=4.16, \quad P=0.041\right.$, odds ratio (OR) 2.8 ; 95\% CI 1.0-7.7) and more helpful than other agencies $\left(\chi^{2}=12.81\right.$, $P<0.001$, OR 7.91 ; 95\% CI 2.4-26.5). Patients' social networks were also deemed more helpful than other agencies $\left(\chi^{2}=8.69\right.$, $P=0.003$, OR 6.1; 95\% CI 1.8-21.4).

Fifteen patients $(25 \%)$ said that their religious beliefs prevented them from attempting suicide. Praying was deemed to have helped a great deal at this time by 4 patients and to have helped a bit by 10 . Of the 15 patients who consulted a minister or priest while at their lowest, 3 derived a great deal and 6 a bit of help. Self-help strategies gave a great deal of help for 16 of the 59 patients $(27 \%)$.

Patients were asked open-endedly what they had considered to be the most helpful factor when they were feeling at their worst. Of the 56 who cited a most helpful factor, this related to someone in their social network for 23 and for 22 patients it comprised some aspect of assistance from psychiatric services.

\section{What was unhelpful?}

When patients were at their worst, 37 $(63 \%)$ were in employment. For these 37 people, 4 perceived work as making no difference to their well-being at this time, 6 thought working helped them, and 27 considered that it made them feel worse.

Patients were asked whether, when at their lowest, items in the media had made them feel even worse or suicidal. Items in newspapers or magazines had done so for 18 patients $(31 \%)$, items on television for $24(41 \%)$ and on the radio for $7(12 \%)$. This was balanced by the 25 patients $(42 \%)$ who reported that something in the media had been positively helpful.

A sizeable majority $(83 \%)$ of patients were conscious of the stigma associated with mental illness when feeling at their worst, and $35(59 \%)$ felt that this stigma had contributed to their feeling at their worst. Twelve patients $(20 \%)$ quantified stigma as contributing 'a great deal' to their feelings at this time.

With regard to substance misuse, only 8 patients $(14 \%)$ had been using nonprescribed drugs, and only $4(7 \%)$ felt that these drugs were a problem. With regard to alcohol, 15 patients $(25 \%)$ were exceeding safe drinking levels, and 11 (19\%) perceived alcohol to have been a problem at that time. Alcohol was perceived as helpful to 17 patients $(29 \%)$ when they were feeling at their worst.

\section{DISCUSSION}

\section{Main findings of study}

Most patients had experienced suicidal feelings and many had acted upon these. Psychiatric services and patients' social networks were deemed particularly helpful, but when at their worst nearly a third of participants were not yet in contact with services and nearly half did not discuss their feelings with people in their social networks. Religion and self-help strategies were also helpful, whereas employment, stigma and the media were generally unhelpful.

\section{Methodological considerations}

Our patients lived in the north-east of Scotland, where there is low geographical mobility, and would thus generally have 
been exposed to one particular range of psychiatric services and voluntary agencies. The participants were middle-aged on average by the time of their interview, and had by this time usually suffered fairly lengthy illnesses. Although this gave rise to their having much experience of severe psychiatric illness, it meant that not all would have had relevant experience of more-recent service developments (e.g. out-of-hours community nursing) while at their worst, and thus these findings may not be generalisable to younger patients.

Our sample of patients with serious and enduring mental illness was small, and was selected through availability and willingness to participate in a lengthy and potentially sensitive interview. Although consultants who provided names of potential participants were asked not to invoke their own inclusion or exclusion criteria, it is possible that patients who were less unwell, more cooperative and more likely to be complimentary about psychiatric services were more likely to be identified. Thereafter, it is possible that self-selection by patients occurred along similar lines. It is noteworthy that participation was much more likely among patients with affective disorders than among those with schizophrenia or schizoaffective disorders. The difficulties of recruiting people with schizophrenia into research studies has been described previously - 'people with predominantly positive symptoms were suspicious of our motives, while those with negative symptoms were unmotivated to take part' (Lester \& Wilson, 1999) - and this unfortunately led to an underrepresentation of their views in our study. Psychological autopsy studies, often because of lack of availability or cooperation of key informants, are also prone to be unrepresentative owing to selective recruitment (Appleby et al, 1999a; Cavanagh et al, 1999). Another shared difficulty with psychological autopsy studies is that ours was necessarily retrospective, but our information did derive directly from the patients themselves without the risk of distortion and of retrospective explanation inherent in the accounts of key informants.

\section{Helpful factors}

Reassuringly, psychiatric services were generally deemed to be helpful. Although the quarter of 'suicide-surviving' patients not in contact with psychiatric services gives rise for concern, it does contrast strikingly with the figures for completed suicide, which show that only a quarter of people committing suicide had contact with psychiatric services during the preceding year (Appleby et al, 1999b). Among our sample, nearly two-thirds of participants had been in contact with their general practitioner, and again this contrasts with lower rates of contact seen in cases of completed suicide (Matthews et al, 1994), especially among young people (Vassilas \& Morgan, 1993). The higher rates of service contact among our 'suicide survivors' and the perceived helpfulness thereof argue strongly that measures directed at enhancing the likelihood of contact with services may be more likely to pay dividends in suicide prevention than measures directed at changing the services themselves, especially when more-intensive interventions do not appear to reduce suicidal behaviour among those with serious mental illness (Walsh et al, 2001). It is noteworthy that many of our patients had attempted suicide and it may be that their contacts with services rendered these attempts less likely to end in a completed suicide.

With regard to patients' reported contacts with people in their social networks, there were two striking findings. Confiding in family and friends was deemed as helpful as contact with psychiatric services, but only $54 \%$ of patients took (or had) the opportunity to do so. There is a vast literature on the relationship between suicide and social support/integration. In summary, social support protects against suicide, but mental illness may reduce the likelihood of experiencing such support (Heikkinen et al, 1993; Johansson et al, 1997; Whitley et al, 1999; Stack, 2000). There are clear implications for the desirability of enhancing supportive social networks among those with mental illness.

The helpfulness of the statutory and voluntary agencies was less apparent, and relatively few patients had contact with these agencies. This may in part reflect the growth of voluntary agencies over recent years which may post-date the period when some of our patients felt at their worst. The findings might also suggest that, notwithstanding the role of organisations such as the Samaritans for suicidal members of the general population, suicide prevention strategies for those with severe mental illness should be targeted in other directions.

Religious beliefs and activities were reported to be helpful. Epidemiologically, there is a fairly consistent negative association between a population's religiosity and its suicide rate (Neeleman et al, 1997). People who commit suicide have been found to be less religious than population controls. In Northern Ireland, this relationship did not endure after controlling for the presence of psychiatric illness (Foster $e t a l$, 1999), but in the USA the protective effects were found to be independent of any increased social contact to which religious activities might give rise (Nisbet et al, 2000).

Self-help strategies were used by a considerable number of patients. This emphasises the need for a balance between active help and intervention on the one hand, and fostering patients' autonomy and self-reliance on the other.

\section{Unhelpful factors}

Although the negative effects of stigma and the media might have been anticipated, the frequency with which these factors were identified as unhelpful was surprising, albeit based on retrospective judgements of events often occurring some years previously. Stigmatisation of people with mental illness is common (Crisp et al, 2000) and its aetiology is complex (Haghighat, 2001; Kendell, 2001). It is likely to be exacerbated by inaccurate representations of psychiatric illness in the media (Berlin \& Malin, 1991), but guidelines and feedback can render media reporting more responsible (Michel et al, 2000). These factors, and the patients' reports in our own study, underline the importance of the Royal College of Psychiatrists' efforts to reduce stigma and improve media coverage of psychiatric illnesses.

Epidemiologically, a fairly consistent relationship emerges between suicide and unemployment (Lewis \& Sloggett, 1998; Gunnell et al, 1999). However, in casecontrol studies some find a positive, independent association between suicide and unemployment (Foster et al, 1999; King et al, 2001) whereas others do not (Beautrais et al, 1998; Appleby et al, 1999a), raising the possibility that suicidal behaviour and unemployment might be linked through the presence of psychiatric illness. Our patients tended to experience work as a difficulty rather than as a help, suggesting that employment per se was not protective against suicidal ideation. That is not to say, of course, that unemployment would have had a less negative impact than did 
the stresses of working while psychiatrically unwell.

\section{Implications and suggestions}

Surprisingly, it seems to be novel to see people with serious psychiatric illness as 'suicide survivors' and to seek their views to inform suicide prevention. Notwithstanding the likely problems in recruitment, a larger and representative cohort who have experienced a wider range of service provision and voluntary agencies should yield data which could be generalised with more confidence. Meanwhile, the findings from our preliminary study with regard to suicide prevention suggest that:

(a) efforts to increase the likelihood that people with psychiatric illness will get in contact with services are more likely to be helpful than changes to those services;

(b) attempts to enhance patients' social networks should be intensified;

(c) patients' religious affiliations should be fostered;

(d) attempts to reduce stigma and improve media coverage of psychiatric illness should continue.

\section{ACKNOWLEDGEMENTS}

We thank the patients who participated in the study During the study, D.P.C. worked at the Health Services Research Unit, Aberdeen, which is funded by the Chief Scientist Office of the Scottish Executive Department of Health. Lana Hadden did the secretarial work on the project.

\section{REFERENCES}

Appleby, L., Cooper, J., Amos, T., et al (1999a) Psychological autopsy study of suicides by people aged under 35. British Journal of Psychiatry, 175 168-174.

_, Shaw, J., Amos, T., et al (1999b) Suicide within I2 months of contact with mental health services: national clinical survey. BMJ, 318, 1235-1239.

Beautrais, A. L., Joyce, P. R. \& Mulder, R.T. (1998) Unemployment and serious suicide attempts. Psychological Medicine, 28, 209-218.

Berlin, F. S. \& Malin, H. M. (199I) Media distortion of the public's perception of recidivism and psychiatric rehabilitation. American Journal of Psychiatry, 148 1572-1576

Cavanagh, J.T. O., Owens, D. G. C. \& Johnstone, E.C. (1999) Suicide and undetermined death in south east Scotland. A case-control study using the psychological autopsy method. Psychological Medicine, 29, ||4I-I|49.

Crisp, A. H., Gelder, M. G., Rix, S., et al (2000) Stigmatisation of people with mental illness. British Journal of Psychiatry, 177, 4-7.

\section{CLINICAL IMPLICATIONS}

- Efforts to improve contact with psychiatric services are more likely to be helpful than changes to those services.

- Patients' social and religious support networks are highly valued and should be fostered.

Efforts to decrease the stigma attached to mental illnesses should continue.

\section{LIMITATIONS}

- The participation rate was relatively low.

- The patients had generally been exposed to psychiatric and voluntary services in only one area of Scotland.

Data were collected retrospectively in a manner that may not have excluded recall bias.

JOHN M. EAGLES, FRCPsych, Royal Cornhill Hospital, University of Aberdeen; DAWN P. CARSON, MRCPsych, University of Aberdeen; ANNABEL BEGG, MB, ChB, Royal Cornhill Hospital, Aberdeen; SIMON A. NAJl, BSc, University of Aberdeen, Scotland, UK

Correspondence: Dr John M. Eagles, Royal Cornhill Hospital, Cornhill Road, Aberdeen AB25 2ZH, UK

(First received 23 May 2002, accepted 30 May 2002)

Eagles, J. M., Klein, S., Gray, N. M., et al (200I) Role of psychiatrists in the prediction and prevention of suicide: a perspective from north-east Scotland. British Journal of Psychiatry, I78, 494-496.

Faulkner, A. \& Thomas, P. (2002) User-led research and evidence-based medicine. British Journal of Psychiatry, 180, I-3.

Foster, T., Gillespie, K., McClelland, R., et al (1999) Risk factors for suicide independent of DSM-III-R Axis I disorder. Case-control psychological autopsy study in Northern Ireland. British Journal of Psychiatry 175, 175-179.

Geddes, J. (1999) Suicide and homicide by people with mental illness. BMI, 318, 1225-1226.

Gunnell, D., Lopatatzidis, A., Dorling, D., et al (1999) Suicide and unemployment in young people. Analysis of trends in England and Wales, 1921-1995. British Journal of Psychiatry, 175, 263-270.

Haghighat, R. (200I) A unitary theory of stigmatisation. Pursuit of self-interest and routes to destigmatisation. British Journal of Psychiatry, $\mathbf{1 7 8}$ 207-215.

Hawton, K., Appleby, L., Platt, S., et al (1998) The psychological autopsy approach to studying suicide: a review of methodological issues. Journal of Affective Disorders, 50, 269-276.

Heikkinen, M., Aro, H. \& Lonnqvist, J. (1993) Life events and social support in suicide. Suicide and Lifethreatening Behavior, 23, 343-358.

Johansson, L. M., Sundquist, J., Johansson, S. E. et al (1997) Ethnicity, social factors, illness and suicide: a follow-up study of a random sample of the
Swedish population. Acta Psychiatrica Scandinavica, 95 |25-13|.

Kendell, R. E. (200I) The distinction between menta and physical illness. British Journal of Psychiatry, $\mathbf{1 7 8}$, 490-493.

King, E. A., Baldwin, D. S., Sinclair, J. M. A., et al (200I) The Wessex Recent In-Patient Suicide Study. I: Case-control study of 234 recently discharged psychiatric patient suicides. British journal of Psychiatry, 178, 53I-536.

Lester, H. \& Wilson, S. (1999) Practical problems in recruiting patients with schizophrenia into randomised controlled trials. BMJ, 318, 1075

Lewis, G. \& Sloggett, A. (1998) Suicide, deprivation, and unemployment: record linkage study. BMI, $\mathbf{3 1 7}$, 1283-1286.

Matthews, K., Milne, S. \& Ashcroft, G.W. (1994) Role of doctors in the prevention of suicide: the final consultation. British Journal of General Practice, 44, 345-348.

Michel, K., Frey, C., Wyss, K., et al (2000) An exercise in improving suicide reporting in print media. Crisis, 2 7|-79.

Mortensen, P. B. (1999) Can suicide research lead to suicide prevention? Acta Psychiatrica Scandinavica, 99. 397-398.

Neeleman, J., Halpern, D., Leon, D., et al (1997) Tolerance of suicide, religion and suicide rates: an ecological and individual study in 19 Western countries. Psychological Medicine, 27, ||65-|17|.

Nisbet, P. A., Duberstein, P. R. \& Conwell, Y. (2000) The effect of participation in religious activities on 
suicide versus natural death in adults 50 and older. Journal of Nervous and Mental Disease, 188, 543-546.

Stack, S. (2000) Suicide: a I5-year review of the sociological literature. Part II: modernization and social integration perspectives. Suicide and Life-threatening Behavior, 30, 163-176.
Vassilas, C. A. \& Morgan, H. G. (1993) General practitioners' contact with victims of suicide. BMJ, 307, 300-301.

Walsh, E., Harvey, K., White, I., et al (200I) Suicidal behaviour in psychosis: prevalence and predictors from a randomised controlled trial of case management.
Report from the UK700 trial. British Journal of Psychiatry, 178, 255-260.

Whitley, E., Gunnell, D., Dorling, D., et al (1999) Ecological study of social fragmentation, poverty and suicide. BMJ, 319, 1034-1037. 